\title{
Peliosis Hepatis due to Corticosteroid in Systemic Lupus Erythematosus
}

\author{
Masatoshi Kimura ${ }^{1}$, Ayako Aizawa ${ }^{1}$, Shunichi Miyauchi ${ }^{1}$, \\ Satoru Hasuike ${ }^{2}$ and Kunihiko Umekita ${ }^{1}$
}

Key words: corticosteroid, liver dysfunction, peliosis hepatis

(Intern Med 58: 1663-1664, 2019)

(DOI: 10.2169/internalmedicine.2167-18)
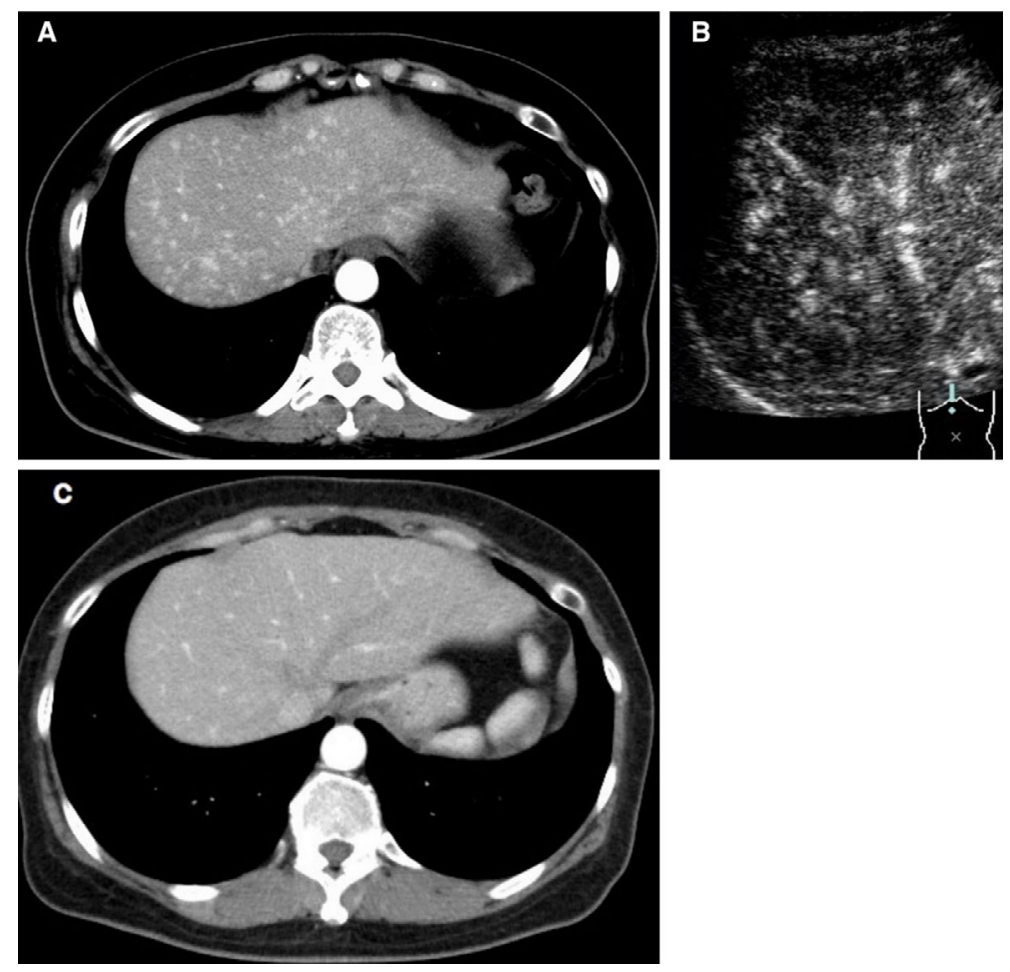

Picture.

A 51-year-old woman was diagnosed with systemic lupus erythematosus (SLE) with nephritis. High-dose corticosteroid and intravenous cyclophosphamide (IVCY) therapy was administrated, and the disease activity of SLE was improved; however, a blood examination showed elevated levels of aspartate aminotransferase, alanine aminotransferase, and gamma-glutamyl transferase after these therapies. Therefore, IVCY was discontinued because drug-induced liver dysfunction was suspected; however, the elevation of liver enzymes continued to worsen. Contrast-enhanced computed tomography showed homogeneous contrast enhancement during the hepatic arterial phase (Picture A). Contrastenhanced ultrasonography using Sonazoid revealed a hyperechoic peliotic lesion (1) (Picture B). These radiological findings strongly suggested peliosis hepatis $(\mathrm{PH})$. A histological examination was not performed because a liver biopsy was

\footnotetext{
${ }^{1}$ Department of Rheumatology, Infectious Diseases and Laboratory Medicine, University of Miyazaki, Japan and ${ }^{2}$ Department of Gastroenterology and Hematology, Internal Medicine, Faculty of Medicine, University of Miyazaki, Japan

Received: September 25, 2018; Accepted: December 5, 2018; Advance Publication by J-STAGE: February 1, 2019

Correspondence to Dr. Kunihiko Umekita, kunihiko_umekita@med.miyazaki-u.ac.jp
} 
considered to carry a high risk of intraperitoneal bleeding. Reducing the dose of corticosteroid improved the liver dysfunction and the radiological findings (Picture C). Most patients with $\mathrm{PH}$ are asymptomatic; however, some afflicted patients have died after developing rupture of peliosis (2). Corticosteroid-induced $\mathrm{PH}$ is reported to be reversible. Therefore, clinicians should recall that corticosteroids are a causative drug of liver dysfunction in daily practice.

The study protocol was approved by the research ethical committees of Miyazaki University Hospital, Miyazaki, Japan.

Written informed consent for publication of this report was obtained from the patient by the author.
The authors state that they have no Conflict of Interest (COI).

\section{References}

1. Iannaccone R, Federle MP, Brancatelli G, et al. Peliosis hepatis: spectrum of imaging findings. AJR Am J Roentgenol 187: W43-W 52, 2006.

2. Sommacale D, Palladino E, Tamby EL, Diebold MD, Kianmanesh AR. Spontaneous hepatic rupture in a patient with peliosis hepatis: a report of one case. Int J Surg Case Rep 4: 508-510, 2013.

The Internal Medicine is an Open Access journal distributed under the Creative Commons Attribution-NonCommercial-NoDerivatives 4.0 International License. To view the details of this license, please visit (https://creativecommons.org/licenses/ by-nc-nd/4.0/).

(C) 2019 The Japanese Society of Internal Medicine Intern Med 58: 1663-1664, 2019 